\title{
Tragedy on grade crossing: driver failure or systemic fragility?
}

\author{
Manoela Gomes Reis Lopes ${ }^{\mathrm{a}, \mathrm{b},{ }^{*}, \text { Rodolfo Andrade de Gouveia Vilela }}{ }^{\mathrm{b}}$, Ildeberto Muniz de Almeida, \\ Odilamar Lopes Mioto ${ }^{\mathrm{d}}$, Mara Alice Batista Conti Takahashi ${ }^{\mathrm{e}}$ and Fernanda Oliveira Perin ${ }^{\mathrm{b}}$ \\ ${ }^{a}$ Post-Graduation in Public Health Program, School of Public Health of Universidade de São Paulo - FSP/USP, \\ São Paulo, Brazil \\ ${ }^{\mathrm{b}}$ Environmental Health Department, School of Public Health- FSP/USP, São Paulo, Brazil \\ ${ }^{\mathrm{c}}$ Public Health Department, Botucatu Medical School of Universidade Estadual Paulista-UNESP, Botucatu, \\ Brazil \\ ' Workers' Health Program (PST- Americana), Americana, Brazil \\ 'Reference Center for Workers' Health (CEREST Piracicaba), Piracicaba, Brazil
}

\begin{abstract}
In 2010, an accident occurred in Americana-SP, Brazil, involving two trains and one bus on a Grade Crossing, when 10 people died and 17 were injured including workers. This paper aims to analyze the accident using the Model of Analysis and Prevention of Work Accidents (MAPA). The method provides observation of work, interviews and analysis of documents to understand precedents of the event in the following stages: to understand the usual work from the involved people, the changes occurred in the system, the operation of barriers, managerial and organizational aspects. By the end, measures are suggested to avoid new occurrences. The accident took place at night in a site with insufficient lighting. The working conditions of bus drivers, train operators and watchmen are inadequate. There were only symbolic barriers (visual and acoustic signals) triggered manually by watchman upon train operator radio communication. The fragility of the barrier system associated to poor lighting and short time to trigger the signaling seem to play a critical role in the event. Contrary to the official report which resulted in guilt of the bus driver, the conclusion of the paper emphasizes the fragility of the safety system and the need of level crossing reproject.
\end{abstract}

Keywords: Health and Safety, Highway, Railway, Work Accidents, Level Crossing

\section{Introduction}

The railway crossing with the road on the same level is called Grade Crossing (GC). Bearing in mind that railway composition has longer time of inertia to its total stopping, these crossings present high risk of accidents even with a lower incidence when compared to other modal roads, but the rate of severity is significant with loss of lives, injuries and material damages. That implies in people's suffering, tax increase for society, burden with payment of indemnities to the victims or their relatives and deterioration of the company's image [1].
A highway composition will only pass through a $\mathrm{GC}$ in a safe way if the installed safety systems are triggered automatically hindering totally the vehicle and people traffic [2]. The barriers are mechanisms whereby it is possible to prevent or to protect against uncontrolled transportation of mass, energy or information. They are used in the control of a certain situation of risk or danger. They can be physical, functional, symbolic or immaterial. The physical barriers are the ones that physically block the propagation of potential energy, the functional barriers are the ones that operate in certain conditions of risk, for example, a system of power interlocking in a machine, and, the symbolic barriers that are the instructions of proce-

\footnotetext{
* Corresponding author. E-mail: lopes.manoela@usp.br. Faculdade de Saúde Pública - FSP/USP, Avenida Doutor Arnaldo, 715, 2ºndar, CEP: 01246-904, São Paulo - SP, Brasil.
} 
dures, warnings, alarms, light signals, etc. The physical and the functional barriers are considered more efficient than the symbolic barriers [3].

Several factors contribute to accidents on GC, such as, for example, factors of physical nature, operational factors of road and railway traffic and behavioral factors [4].

The rate of accidents measures the operational safety of railway transportation indicating the quality of the service offered. This rate is used as a target performance on the railway concession contracts. From 1997 to 2005, there was a reduction of $56 \%$ in the rate from 75.5 to 32.9 accidents per million trains $\mathrm{x} \mathrm{km}$. Despite this reduction, Brazilian indicators remain above the recommended which is 8 to $13 \mathrm{ac}-$ cidents per million trains $\mathrm{x} \mathrm{km} \mathrm{[5].}$

The number of accidents of this nature is being reduced since 1992 and the ones occurred in urban environment such as running over and vehicle crash are priority, which are not decreasing at the same intensity as the occurrences registered resulting from permanent way and equipment [6]. Permanent way is defined as every railway track, the buildings, the telegraph roads, etc [7].

It is important to identify the parameters that influence on the criticality of the crossings to classify the GC and thus to prioritize the interventions and adaptations of signaling. The potentiality of risk on a level crossing is directly related to the type of highway, number of lanes, the conditions of pavement, the highway traffic volume, the pedestrian traffic, the maximum speed limit on the highway, the lighting, the stopping sight distance, number of tracks, the railway traffic volume, the history of accidents and the slope conditions [1].

According to Federal Highway Administration [8], three sight distances of the train are considered on a grade crossing: a) the distance in front of the crossing; b) distance along the track in which a train can be approaching the crossing from any direction; c) sight distance along the tracks in any direction of a vehicle stopped on the crossing (Fig. 1).

The priority of a GC is evaluated for its safety not only for the risk of an accident but also for the people traffic and insufficient or inadequate signaling. Another major point to be evaluated is the location of the $\mathrm{GC}$ as well as its interference in the urban traffic of vehicles (gridlocks and interruptions) and if the $\mathrm{GC}$ is clandestine or irregular [5].

According to the data from Planning Commission of National Association of Railway Transport (ANFT), there are about 12,400 grade crossings in Brazil of which around 2,503 were classified as criti- cal [9]. Among these critical GCs there are 134 priority critical GCs. The Southeastern Region presents 62 priority critical GCs, of which 29 are in State of São Paulo with an estimated intervention of R\$ 115.79 million [5].

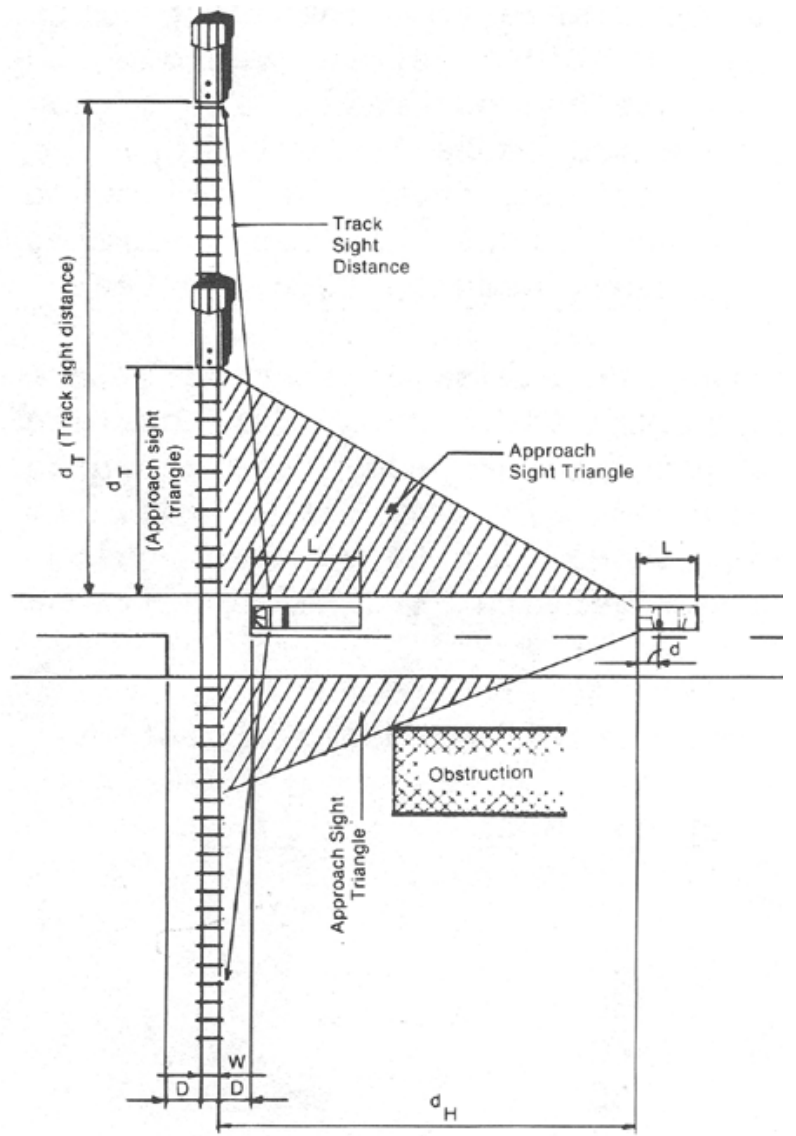

Fig. 1. Sight distances for crossing on a grade crossing.

Source: Railroad-Highway Grade Crossing Handbook, Second Edition. Washington, DC: U.S. Department of Transportation, Federal Highway Administration, 1986.

In Americana-SP the GC situated on the crossing of Carioba Street is classified by ANTF as one of the Priority Critical for which the proposed solution is its substitution for a grade separation with an estimated cost of $\mathrm{R} \$ 2$ millions. This GC is located in the rail yard used for crossing and switchings, presenting great flow of vehicles and pedestrians in central region of the city [9].

On September $8^{\text {th }}, 2010$, approximately at 11:25P.M. an accident happened involving two trains and one bus on this GC. Pushed about 100 meters, the bus was guillotined when it was hit by another one that was parked on parallel line. The involved 
composition while in movement had four locomotives and 77 railway cars, each one weighing 100 tons and was carrying corn, soybean and sugar to be exported by ships at Port of Santos.

This is an enlarged accident involving ten victims and seventeen injured people. The Workers' Health Program - PST from Americana-SP registered four work accidents in the event [10].

This paper aims to analyze the immediate and latent causes of the accident attempting to avoid or minimize the chances of similar events to happen in the future.

\section{Method}

In order to carry out the analysis, the Model of Analysis and Prevention of Work Accidents - MAPA was used [11], the method adopted by the Work Accident Surveillance System - SIVAT from CEREST Piracicaba-SP were used. The method is one of the main products developed by interinstitutional research involving CEREST Piracicaba and the Regional Administration from Ministry of Labor - Piracicaba with Universities (Methodist University of Piracicaba - UNIMEP, Botucatu Medical School UNESP/Botucatu and School of Public Health of University of São Paulo - FSP/USP). The research in the public policies area was supported by São Paulo Research Foundation - FAPESP Proc. No 06/51684-3.

The use of MAPA aims: to identify the multiple factors of accidents, which interaction was bound to the event, especially the most upstream injury ones, related to organizational and managerial aspects of the system concerned; to investigate the situation of normal work and the causes of changes and alterations that occurred, contributing to the event, as well as the analysis of the existing barriers and its effective operation; to spread the understanding of work accidents as phenomena resulting from network of factors in interaction, surpassing the dichotomous vision (actions/unsafe conditions); to evaluate, with the analysis of the specific case, the factors related to the management of risks adopted in the system contributing to the prevention of new events; to subsidize other organizations' and institutions' actions.

In order to achieve these goals the description of usual work without accidents is carried out, based on the ergonomics concepts; report of misfortune itself; analysis of changes and barriers present in the situation. The analysis also explores aspects of production and safety management seeking to understand latent conditions of the accident and to enlarge the perimeter of the preventive intervention [11].

This study involved professionals from different institutions: Workers' Health Program (PST- Americana), Reference Center for Workers' Health (CEREST-Piracicaba), Ministry of Labor - Regional Administration of Labor (GRTE) in Campinas, School of Public Health - USP and Medical School- Public Health Department of UNESP- Botucatu.

The analysis based on articles, books, newspapers and TV reports about the subject. After this phase, interviews were carried out with workers from the bus company, the railway company and the public authority - drivers, conductors, train operators and watchmen - as well as with the workers involved in the accident and with one of the surviving passengers.

After the collected information was systematized, an analysis of data was accomplished with the understanding of the researchers about the findings and it was concluded with recommendations on necessary interventions.

\section{Results}

The results presented are preliminary, whereas they reflect the current stage of the study.

The bus was hit on the GC by a train coming from the left towards the right and pushed against another train parked about 100 meters to the right. According to the bus driver's report, the traffic light was red when the vehicle was in the middle of the GC. Figure 2 presents diagram of the $\mathrm{GC}$, the location of two trains and the bus at crossing moment on the GC resulting the accident.

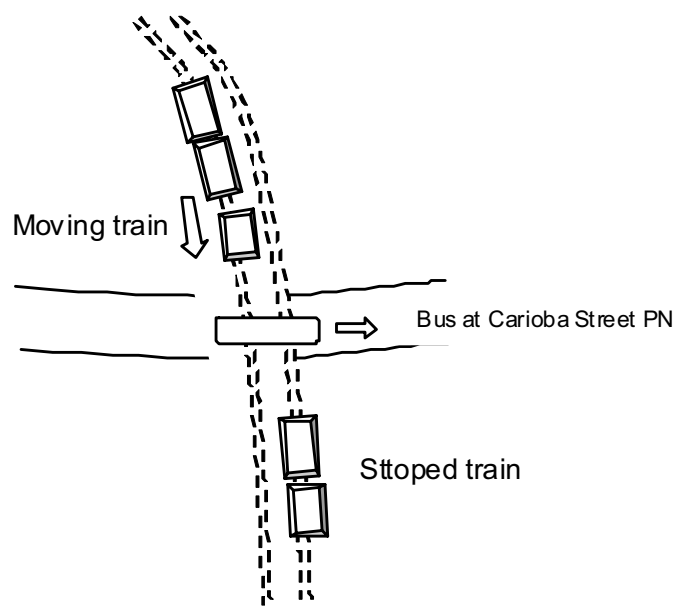

Fig. 2. Diagram of the accident site. 
The site is poorly lit what hampers the visualization of trains coming from the left. Besides this, there are buildings under construction next to the GC, that obstruct the visualization of the trains coming to it, at the crossing moment. At this site one can also find out the land presents strong undulations near by the tracks, calling the drivers for decreasing the speed of vehicles during the crossing of railway track.

The accident took place at night (Fig. 3), at about 11:25P.M., a few hours before the train was supposed to be withdrawn. On the GC there is heavy traffic of cars, motorcycles, buses and pedestrians (Fig. 4). After two months of the accident, a manual gate was installed to block the traffic of people and vehicles during the crossing of trains on the GC. This gate is closed manually by the watchman who stays on duty upon train operator radio communication, who warns when he's approaching and he's going to cross the GC.

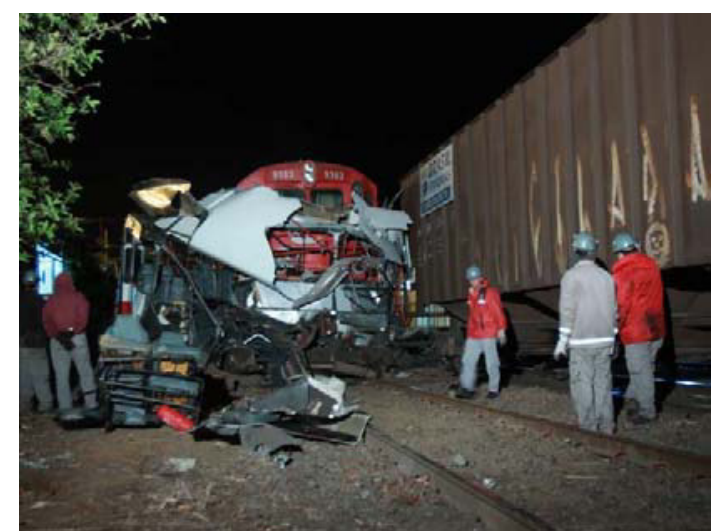

Fig. 3. Picture of the Accident in Americana-SP. Source: Macedo, 2010.

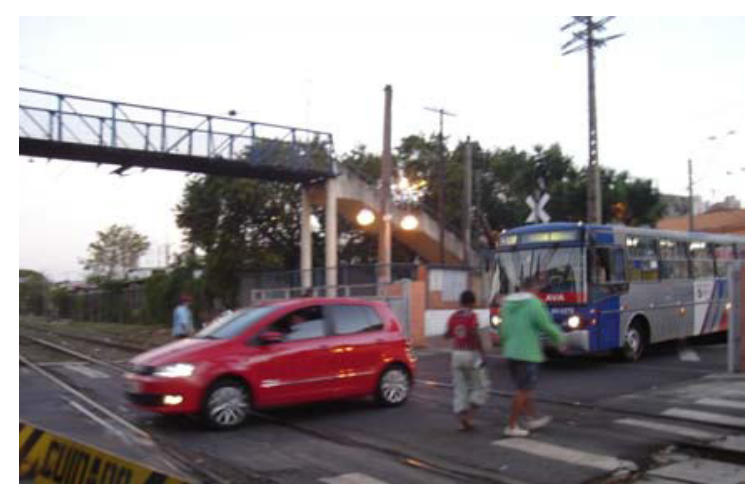

Fig. 4. The dinamics of the Grade Crossing in Americana-SP.

According to the drivers, the work of bus conduction is stressful, the conditions are inadequate and it includes regular practice of extra hours.
The work, on the accident day, in conformity to the driver's description, went by normally during all day long. He started working at 2:00P.M., as usual, and took over his routine track and he had been working for $9 \mathrm{~h} 30 \mathrm{~min}$ when the event occurred. These daily hours were common to the driver, working about two extra hours a day. The work system is arranged in a six-hour working days for one day off (6x1).

The bus drivers accomplish different working days regulated by MTE and some of them don't obey the legal eleven-hour rest break.

Collective agreement of the category provided the suspension of meal break that started to be taken during a time of lower flow of passengers and they should accelerate a little on the way to have a reserve of time.

The meal is taken from home in a lunch box and it is put under the driver's seat, which keeps it warm near the engine. He says that some drivers put their lunch boxes beside the engine radiator in a carton box, in an empty space they call "microwave".

The train operators' work also occurs with long working hours and terrible accommodation conditions. According to these workers interviewed the long working hours are from 12 to 13 daily hours, and occasionally 35 hours without a break, without leaving the place of work. They mention they do not have a fixed schedule to start working, being available for the company. The company maintains accommodations where the workers can stay at night if they have to interrupt the length. These accommodations are beside the railway with traffic of trains and in some places present problems concerning the cleaning of the sheets and blankets for collective use.

It was said that depending on the company, the process of training is different, varying from three months to two years. In a train operator report it was evidenced the training should take at least two years for an assistant and then becoming a train operator. Besides that, there are several gaps in terms of salary, regular food supply and working hour periods.

The watchmen are civil servants hired by the Town Hall of Americana, and they present a six-hour working day whose function is to monitor and to guarantee the safety of the GC.

The watchman's place of work is a guard house without any comfortable conditions, located very close to the railway track, causing fear of train derailment in these workers. The restroom does not present good conditions either (for example, improvised with an empty hole space on the wall), also used as a stock room of the railway company. They 
allege the cleaning of both places is carried out by the watchmen themselves.

The automatic triggering of alarms near the GC was deactivated and replaced by a radio communication. This decision will be object of further research and it seems to have originated from pressure from traders and passers-by who used to complain about the interruption of traffic flow on the place.

Nowadays, when the train is 2 or $3 \mathrm{~km}$ away from the $\mathrm{GC}$, the train operator warns the watchman by radio communication if he is going to cross the GC or to stop before it. The watchman is supposed to the triggering of the light and sound signal when he receives the warning that the train is going to surpass the $\mathrm{GC}$, and after the accident he is due to close manually the gate. The train operator is supposed to trigger the train horn 500 meters away from the GC.

Even with the signal triggered it is perceptible that people nowadays cross this signal while the gate is not completely closed. It occurs in the same way when the watchman opens the gate after the train passing, and some seconds after the opening of the gate the vehicles pass very close to the watchman, who is in danger of being run over.

At the time the accident happened there were only symbolic barriers operating (visual and acoustic ones), considered weak [3] because they do not prevent the cars from passing by when the trains are approaching. The people interviewed said they had seen accidents on GC, which confirmed the fragility of the system.

Regarding the acoustic and visual signal, both of them are triggered at the same time. It was reported it is not common, but the signal can fail sometimes, whereas maintenance of the system is not preventive but corrective. The same happens to the train horn sometimes.

If there are delays or failures of the train operator and/or watchman however minor they may be, like the case suggests, it can imply in late triggering of symbolic barriers (light signal triggered by the watchman, or acoustic signal triggered by train operator) evidencing the fragility of the safety system.

This fragility is reinforced by the difficult visualization of train approaching, by the bus driver, resulting from the existence of sharp curve on the railway track which contests the location recommendations of the GC. Other complementary symbolic barriers such as the proceedings of train horn approaching the $\mathrm{GC}$ is also weak, whereas, they depend on the triggering by the train operator and they can find obstacles to his hearing like the location of buildings under construction along the railway track and the concomitance with other noises.

The train speed is also crucial for the safety system, whereas a highest speed decreases the time to trigger the light and acoustic signal.

Due to the presence of buildings under construction and curves near the GC under analysis, the visualization of trains at the crossing time is harmed.

It is realized by the verbalization of the watchman that his performance is dependent on and interconnected to the communication to be emmitted in time by the train operator, mediated by the requirement of perfect radio operation in order to symbolic barriers be able to be triggered in time. The safety system depends on a perfect and harmonic interaction among all these components and by the need of braking and interruption of vehicles flow by the drivers and other passers-by, which evidences the fragility of the safety system.

In spite of the complexity and the interaction of multiple factors, the accident was investigated by the Institute of Forensic Science which has considered the bus driver guilty of the occurrence, nowadays being object of criminal procedure and may be condemned and arrested.

\section{Discussion}

Brazil is considered the world Record holder in work accidents with three deaths every two hours and three non-fatal work accidents every minute [12] that is they represent an important issue to Public Health due to the magnitude of statistical data s well as the consequences of suffering and death to the workers involved in these accidents and theirs families.

Binder and Almeida [13, p. 770] comment that in spite of the noun accident suggests something sudden and unexpected, "[...] it is about predictable phenomena, although it is not possible to predict when exactly they will happen and which workers will be involved. And, overall, they can be prevented with neutralization or elimination of factors that are able to unleash them."

Work accidents are caused by the interaction of technical, organizational and human factors. Unfortunately, in the transportation sector there is still a widespread concern about the "human factors" [14].

Such view reduces the occurrence to an event of a few causes, impairing the analysis and identification of the original factors [15].

Another matter to be emphasized is that the accident reveals aspects of the organization history which 
were contrived not only in horizontal relationships position but also in the vertical ones in work situations [15].

The same authors explain that according to this view the existence of train operators' mistakes and failures is not disregarded, however it's necessary to extend the analysis to understand the origins of these errors and failures. In other words it is necessary to search the latent causes or the causes of causes of these events.

Unfortunately, most of the reports are still based on the concept of duties making us think human factor is the causer of the event.

Among the transportation occurrences and accidents, the traditional approach predominates and it attributes to the human factors from $60 \%$ to $80 \%$ of the responsibility for the accidents, in which the operators are at the same time actors of safety and one of the main failure causes. However the analysis of the accident cannot be restricted only to the operator, one should take into account his activity conditions the equipment he uses, the rules in effect and their application. Besides that, the safety knowledges are not supposed to be considered static and definitive ones [14].

According to Fornaro [2], the problems resulting from the $\mathrm{GC}(\mathrm{s})$ on the territory reverberate especially on the sites of their existence, but, if they were analyzed on the whole GC(s) that exist on national railways, the width of the issue would be enlarged. When an accident occurs on a GC, the fact is local and the disaster is punctual and isolated. Although the accidents do not occur very often on several locations, constantly risking people's life, becoming into a safety issue to the State and to the population. The analysis of the case revealed the managers of railway system used to dispose of criticism diagnosis of several GCs all over the country, however without taking urgent actions to avoid the repetition of tragedies such as the one present studied.

The analyzed accident is result of a complex interaction of several components of the system, where the time to trigger the signal seems to have played a critical role. The symbolic barriers (light and acoustic ones) weak by nature, seem not to be triggered in time, which adequate operation depends on a closely together communication between the train conductor and the watchman, which even when triggered they are subject to failures and defects (what has not occurred in the present case), these variations are not included in any redundant system to supply the susceptible safety. The fragility of barriers was associated to the driver's difficulty to visualize the ap- proaching train which traveled in speed, on a curve situated in a location with buildings and obstacles. The consequences of the accident were potentiated by the presence of a second train that allowed the formation of a guillotine effect, rupturing the bus structure.

It was concluded the need of a complete reproject of the GC. The installation of a gate creates a physical obstacle to the pedestrians and vehicles, but the system continues depending on the human action to close the gate, which depends on the perfect communication between the train operator and the watchman, considered vulnerable points that participated in causal chain of the accident.

Reproducing the traditional approach in an uncritical way, the analysis performed by official experts from Institute of Forensic Science resulted in the culpability of the driver about the occurrence, disregarding the complexity present in event that originated from the interaction of, at least: the bus driver, the trains operators, the watchmen in charge of the signaling of approaching trains, the responsible for conception and maintenance of safety management on the GC and the workers in charge of urban road and public lighting. The official analysis puts on the bus driver all the responsibility of the complex and multiple causal event to his behavior. It also favors the judicial defense of the companies and institutions involved in the management of road and rail transportation system, to the detriment of improvement in reliability and safety of the system.

The approach which guided the analysis is that the work accidents are complex sociotechnical and mutiple caused events, influenced by factors related to the immediate working situation such as the machinery, the duty, the technical or material mean, and also by working organization and by working relationships. The great challenge, for actual comprehension of the accidents is to understand what has changed in the working situation, how and why these changes in the routine destabilize the system and result in the unwelcome event.

The analysis carried out by the multi-institutional team calls the attention to the need of considering the history of common practices on that GC, narrated by the interviewed people, concludes with a systemic explanation of the accident, stimulating the organizational learning and the renovation of safety practices, in order to implement more efficient protection action for prevention of new occurrences not only on this grade crossing but also on the all the ones that are considered critical all over the country. 


\section{Acknowledgements}

The team is very grateful to Gil Vicente Fonseca Ricardi, Tax Auditor from Ministry of Labor, for his support in the leading of the case.

\section{References}

[1] Carmo RC, Campos VBG, Guimarães JE. Procedimento para Avaliação da Segurança de Passagens de Nível. Anais do XXI ANPET - Congresso de Ensino, Pesquisa. Rio de Janeiro, 2007.

[2] Fornaro AC. Passagens em nível nas ferrovias brasileiras: algumas implicações para os sistemas de transportes e para a população. Campinas (SP). Instituto de Geociências, UNICAMP, 2009.

[3] Hollnagel E. Risk + barriers $=$ safety? Safety Science. 2008;46(2):221-9.

[4] Carmo RC, Campos VBG. Indicador de nível de segurança para passagens de nível. In: $5^{\circ}$ Concurso de Monografia CBTU-2009. 02 dec. 2010. Available from: http://www.cbtu.gov.br/

monografia/2009/trabalhos/artigos/gestao/4_222_AC.pdf.

[5] Lang AE. As ferrovias no Brasil e avaliação econômica de projetos: uma aplicação em projetos ferroviários. Brasília: Universidade de Brasília, 2007.

[6] Villar LB, Marchetti DS. Dimensionamento do potencial de investimentos para o setor ferroviário. BNDES Setorial. n. 24, 2006 .
[7] DNIT - Departamento Nacional de Infraestrutura de Transportes. Glossário de termos ferroviários. 02 dec. 2010 Available from: http://wwwl.dnit.gov.br/ aplweb/sis glossario/Consulta.asp.

[8] Federal Highway Administration. Railroad-Highway grade crossing. 2 ed. New Jersey, 2007.

[9] ANTF - Associação Nacional dos Transportadores Ferroviários. Plano Estratégico para o desenvolvimento do setor de transporte ferroviário de cargas. Brasil nos Trilhos. Brasília. CD Rom 7 files, 123MB, 2006.

[10] Macedo L. Passageira conta como foi acidente envolvendo trem e ônibus em SP. 26 nov. 2010. Available from: http://g1.globo.com/sao-paulo/noticia/2010/09/passageiraconta-como-foi-acidente-envolvendo-trem-e-onibus-emsp.html.

[11]Almeida IM, Vilela RAG. Modelo de análise e prevenção de acidente de trabalho-MAPA. Piracicaba: CEREST, 2010.

[12]Fachini LA, Nobre LCC, Faria NMX, Fassa AG, Thumé E, Tomasi E, Santana VS. Sistema de Informação em Saúde do Trabalhador: desafios e perspectivas para o SUS. Ciência \& Saúde Coletiva. 2005; 10(4): 857-67.

[13]Binder MCP, Almeida IM. A contribuição da Ergonomia para a identificação, redução e eliminação da nocividade do trabalho. In: Mendes RA. Patologia do trabalho. Belo Horizonte: Atheneu, 2002.

[14] Valot CO. Transporte, a segurança e a ergonomia. In: Falzon P, organizador. Ergonomia. São Paulo: Blucher, 2007. p. 57386.

[15] Vilela RAG, Iguti AM, Almeida IM. Culpa da vítima: um modelo para perpetuar a impunidade nos acidentes do trabalho. Cad. Saúde Pública. Rio de Janeiro. 2004; 20(2):570-9. 